\title{
Comparative Study of Nanobioactive Glass Quaternary System 46S6
}

Mabrouk $\mathrm{M}^{1,2}$, Mostafa $\mathrm{AA}^{1,2 *}$, Oudadesse $\mathrm{H}^{1}$, Wers $\mathrm{E}^{1}$, Lucas-Girot $\mathrm{A}^{1}$ and El-Gohary $\mathrm{MI}^{3}$

${ }^{1}$ University of Rennes 1, UMR CNRS 6226, 263 av. du général leclerc, 35042 Rennes cedex, France

${ }^{2}$ Biomaterials Department, National Research Centre (NRC), Cairo, Egypt

${ }^{3}$ Physics Department, Faculty of Science, Al -Azhar University, Cairo, Egypt

\begin{abstract}
Different bioactive glass systems have been prepared by sol-gel. However, the production of Na2O-containing bioactive glasses by sol-gel methods has proved to be difficult as the sodium nitrate used in the preparation could be lost from the glass structure during filtration and washing. The aim of this study was to prepare the quaternary system $46 S 6$ of bioactive glass by modified sol-gel techniques with a decrease in the time of gelation. In addition, compare the behaviour of the prepared sol-gel bioactive glass system by its corresponding prepared by melting. The obtained glasses were characterized by using several physicochemical techniques; XRD, FTIR, TEM and SEM beside the effect of the glass particles on the viability of osteoblast like cells (Saos-2). Results show that nanopowders 40-60 nm of $46 \mathrm{~S} 6$ glass system had been prepared by modified sol-gel (acid-base reaction) method at $600^{\circ} \mathrm{C}$ in just three days at $600^{\circ} \mathrm{C}$. Cell viability by MTT assay confirmed the effectiveness of the prepared nanobioactive glass.
\end{abstract}

Keywords: Nanoshperes; bioactive glass; sol-gel; melting; 46S6; Heat treatment and cell viability

\section{Introduction}

Among the production methods of bioactive materials stands out the sol-gel processing. The prepared materials with high purity, homogeneity and lower processing temperatures could possibly be obtained [1]. Commercially available glass compositions; 45S5, 52S4, $58 \mathrm{~S}$ and $64 \mathrm{~S}$ could be synthesized by sol-gel method [2-4]. Addition of some elements such as $\mathrm{K}_{2} \mathrm{O}$ and $\mathrm{Na}_{2} \mathrm{O}$ used in conventional melting, reduce the melting temperature and makes the final materials are more soluble in aqueous media. This factor is extremely important for the interaction of the materials with the living tissues. However, to the best of knowledge nanobioactive glass $46 \mathrm{~S} 6$ system containing high amount of $\mathrm{Na}_{2} \mathrm{O}$ has not been achieved yet. The particle size of the traditional sol-gel-derived bioactive glasses was bigger than $1 \mu \mathrm{m}$ [5] because of the long gelation and ageing time $[4,5]$. The objective of this study was to prepare the quaternary system $46 \mathrm{~S} 6$ of bioactive glass by modified sol- gel techniques in shorter time as previously mentioned. In addition, comparing the behaviour of the prepared bioactive glass system by sol-gel named (SG-B) by its corresponding system prepared by melting technique named (MB) by means of XRF, XRD, FTIR, TEM and SEM before and after immersion in simulated body fluid (SBF). Furthermore, the viability test was conducted on the Saos- 2 cells using MTT assay.

\section{Synthesis and Characterizations}

\section{Synthesis}

The $46 \mathrm{~S} 6$ bioactive glass with the composition $\left(46 \% \mathrm{SiO}_{2}, 24 \%\right.$ $\mathrm{CaO}, 24 \% \mathrm{Na}_{2} \mathrm{O}, 6 \% \mathrm{P}_{2} \mathrm{O}_{5}$ wt $\%$ ) was prepared by melting as previously reported [6]. The used chemicals were calcium silicate (Alfa Aesar), trisodium trimeta phosphate and sodium metasilicate pentahydrate (Sigma). The prepared glass by melting technique was named MB. However, the bioactive glass with the same composition was prepared by sol-gel technique and named SG-B. Tetraethyl orthosilicate (TEOS: Fluka, wt=208.33), $56 \mathrm{ml}$ was added to $50 \%$ ethanol at room temperature. The $\mathrm{pH}$ was adjusted at 2 by nitric acid with continuous stirring for $1 \mathrm{~h}$. Addition of $24.5 \mathrm{~g}$ of calcium nitrate hydrate (Fluka, M.wt=236) and then, $21.07 \mathrm{~g}$ of sodium hydroxide (Prolab, M.wt=40) were added to the above mixture (the previous mixture was named solution A). Polyethylene glycol (PEG-Fluka M.wt=600) $10 \mathrm{~g}$ was dissolved in distilled water at room temperature then, $3.43 \mathrm{~g}$ of ammonium dihydrogen phosphate (MERK, M.wt=115.03) was added to the PEG solution, this mixture was named solution B. Solution (B) was gradually added to solution (A) with continuous stirring over night in a Teflon container. The resulted solution was filtered and washed with distilled water 3 times and then with ethanol by using centrifuge at $1650 \mathrm{rpm}$ for $10 \mathrm{~min}$ each. Drying of the washed gel at $70^{\circ} \mathrm{C}$ overnight and then calcination at $600^{\circ} \mathrm{C}$ for $2 \mathrm{~h}$ have been performed.

\section{Characterizations}

The thermal analysis of both MB and SG-B powders were investigated by DSC/TG. The structural and morphological properties were characterized by using XRF, XRD, FTIR, TEM and SEM. For evaluation of the in-vitro bioactivity, $100 \mathrm{mg}$ of powders were immersed in $200 \mathrm{ml}$ of SBF at different times (2, 5 and 7 days). Furthermore, the granules were filtered, cleaned with ethanol, and dried at $60^{\circ} \mathrm{C}$ overnight. The Physicochemical properties of the filtered granules were studied by XRD, FTIR and SEM. Cell viability test was conducted on Saos- 2 cells to evaluate the biocompatibility of the prepared bioactive glasses materials by the 3-(4,5-dimethyl-2-thiazolyl)-2,5-diphenyl-2Htetrazolium bromide (MTT) assay.

\section{Results and Discussion}

DSC/TG analysis was employed to determine the thermal characteristics of the investigated powder samples as in Figure 1. For the prepared powder samples $M B$ and SG-B, three characteristics peaks at $559^{\circ} \mathrm{C}, 727.6^{\circ} \mathrm{C}$ and $1235^{\circ} \mathrm{C}$ and at $550.6^{\circ} \mathrm{C}, 605.5^{\circ} \mathrm{C}$ and $835.8^{\circ} \mathrm{C}$ corresponding to the temperature of vitreous transition

*Corresponding author: AA Mostafa, University of Rennes 1, UMR CNRS 6226 263 av. du général leclerc, 35042 Rennes cedex, France, Biomaterials Department, National Research Centre (NRC), Cairo, Egypt, Tel: +201006600 620 ; E-mail: amany.mostafa@univ-rennes1.fr; amani.mostafa@gmail.com

Received Decenber 31, 2013; Accepted January 05, 2014; Published January 12,2014

Citation: Mabrouk M, Mostafa AA, Oudadesse H, Wers E, Lucas-Girot A, et al. (2014) Comparative Study of Nanobioactive Glass Quaternary System 46S6. Bioceram Dev Appl 4: 072. doi: 10.4172/2090-5025.1000072

Copyright: (c) 2014 Mabrouk M, et al. This is an open-access article distributed under the terms of the Creative Commons Attribution License, which permits unrestricted use, distribution, and reproduction in any medium, provided the original author and source are credited. 
(Tg), crystallization temperature (Tc) and temperature of fusion (Tf), respectively have been presented. The thermal stability is the stability of a molecule at high temperatures; i.e. a molecule with more stability has more resistance to decomposition at high temperatures. It corresponds to $\left(\mathrm{Tc}-\mathrm{Tg}\right.$ ) and equal to $168^{\circ} \mathrm{C}$ and $54.9^{\circ} \mathrm{C}$ for MB and SG$\mathrm{B}$, respectively. This means that sol-gel method induces decreasing of $46 \mathrm{~S} 6$ bioactive glass thermal stability than melting method. Variation in thermal stability affects on the chemical stability of the prepared glasses and suggests higher bioactivity [7]. Figure 2 shows the XRD patterns of the $46 \mathrm{~S} 6$ bioactive glass prepared by melting technique (MB) at $1350^{\circ} \mathrm{C}$ and by sol-gel method at different heating temperatures from $70^{\circ} \mathrm{C}$ overnight to $600^{\circ} \mathrm{C} / 2 \mathrm{~h}$.

The characteristic peak of MB presents a diffraction halo between $20^{\circ}$ and $37^{\circ}(2 \theta)$ with centre at $32^{\circ} \mathrm{C}$. However, SG-B shows this halo without others at $600^{\circ} \mathrm{C}$ during $2 \mathrm{~h}$ i.e. above the $\mathrm{Tg}\left(550^{\circ} \mathrm{C}\right)$ and below Tc $\left(605.5^{\circ} \mathrm{C}\right)$ as confirmed by DSC/TG results and as reported for the XRD of silicate glass [1].

Figure 3 shows the FTIR spectra of the MB and SG-B at $600^{\circ} \mathrm{C} / 2 \mathrm{~h}$. The spectrum of both samples indicates the same chemical structure as the finger print region is almost the same. It presents the characteristic of silicate absorption bands at $467,945 \mathrm{~cm}^{-1}$ and that of phosphate groups at 600,740 and $1045 \mathrm{~cm}^{-1}$ as reported $[1,7,8]$. A band at 1653 $\mathrm{cm}^{-1}$ attributed to $\mathrm{C}-\mathrm{O}$ resonance in $\mathrm{CO}_{3}^{2-}$ group is detected and another

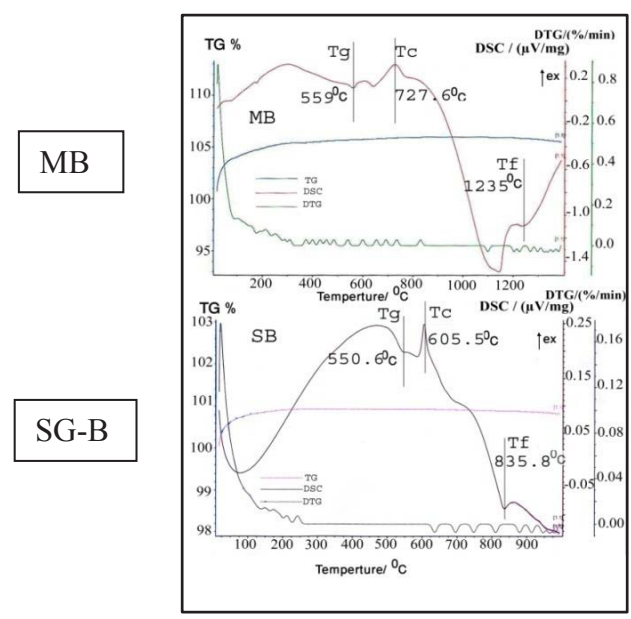

Figure 1: DSC /TG for MB and SG-B.

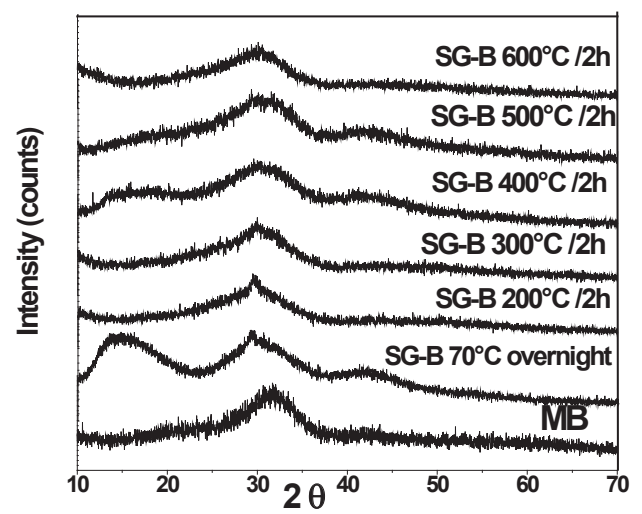

Figure 2: $\mathrm{XRD}$ of the prepared bioactive glasses at different treating temperature. at $3460 \mathrm{~cm}^{-1}$ characteristic to $\mathrm{Si}-\mathrm{OH}$ is clearly observed for sample SGB. [9]. Certainly, it is clear that using of different preparation methods for the same chemical composition does not affect on the nature of chemical bonds between atoms. The quantitative analysis of the prepared powder samples MB and SG-B were determined by XRF. The chemical composition of MB and SG-B was presented in Table 1. It is obvious that the two samples have the same chemical composition with small fractions of impurities $(0.892 \%$ for MB and $0.406 \%$ for SGB). This means that SG-B has less impurities than MB. Therefore, this confirms that the prepared $46 \mathrm{~S} 6$ bioactive glass by sol-gel method has a high purity and considers as good for cell viability [1].

TEM is a powerful tool for observing the morphology and size of particles. Figure 4 shows the TEM micrographs of the prepared samples, MB shows agglomerated sphere particles (Figure 4a) however, SG-B shows highly homogenous nano-spheres ranging between 40-60 nm (Figure $4 \mathrm{~b}$ ). These differences in the homogeneity and particle size are referring to the preparation methods. One-step acid catalysis bioactive glasses require long gelation times. This allows for the aggregation and growth of colloidal particles in the solution, leading to final products with microscale particle sizes [10]. However, in this work, two-step; acid-base catalysis was followed. The addition of sodium hydroxide, as a second catalyst, to the sol that was initially catalyzed by nitric acid was found to raise the rate of condensation and decrease gelation time to few hours. The condensation rate is proportional to [OH-] above the isoelectric point. In this study, sodium hydroxide was used as source of $\mathrm{Na}_{2} \mathrm{O}$ and for gelation to provide an environment of a $\mathrm{pH}$ much higher than the isoelectric point of silica [11].

Figure 5 shows the XRD patterns for MB (Figure $5 \mathrm{a}$ ) and SG-B (Figure 5b) before and after immersion in SBF at different time intervals (2, 5 and 7 days) in reference to the pattern of synthetic hydroxyapatite. After two days of immersion in SBF solution, two characteristic amorphous peaks of hydroxyapatite (HA) at $25.80^{\circ}$ and $31.79^{\circ}$ are observed for the sample SG-B (Figure $5 \mathrm{~b}$ ). The intensity and degree of crystallinity of these peaks increases with the increasing of the

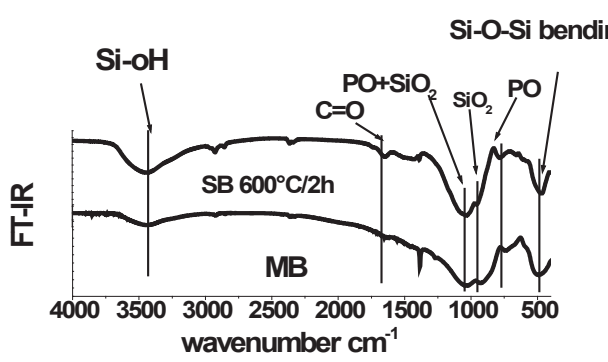

Figure 3: FTIR for MB and SG-B.

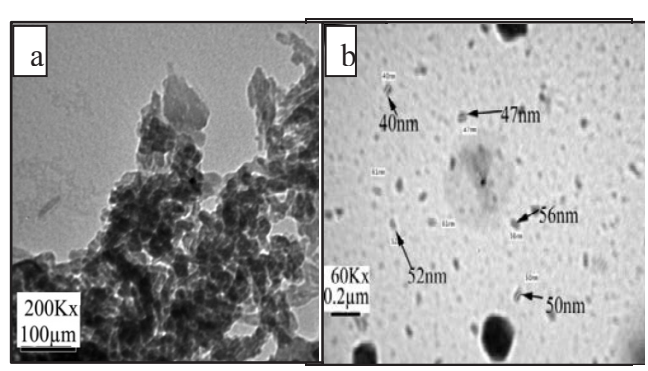

Figure 4: TEM image of a. MB b. SG-B 
soaking time as it is clearly observed with high crystallinity after five and seven days of immersion. It is also notable the appearance of new peak at $45.142^{\circ}$ with higher intensity than that observed in synthetic HA. This could be due to the over lapping of this peak with the peak of Rhombohedral calcium phosphate with that appears at $56.462^{\circ}$ as previously reported [7]. On the other hand for MB after two and five days of immersion we can't observe any characteristic peaks for HA, but after seven days two characteristic peaks for HA at $25.80^{\circ}$ and 31.79 could be observed. This confirms the high reactivity of the glass sample prepared by sol-gel than that prepared by melting.

Figure 6 shows the FTIR for samples MB and SG-B before and after
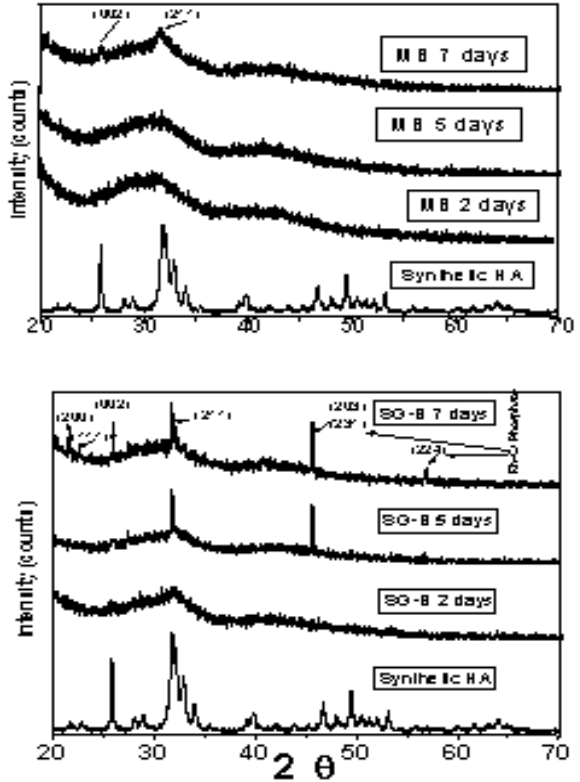

Figure 5: XRD for samples $a . M B$ and $b$. SG-B before and after immersion in SBF for 2, 5and 7 days.
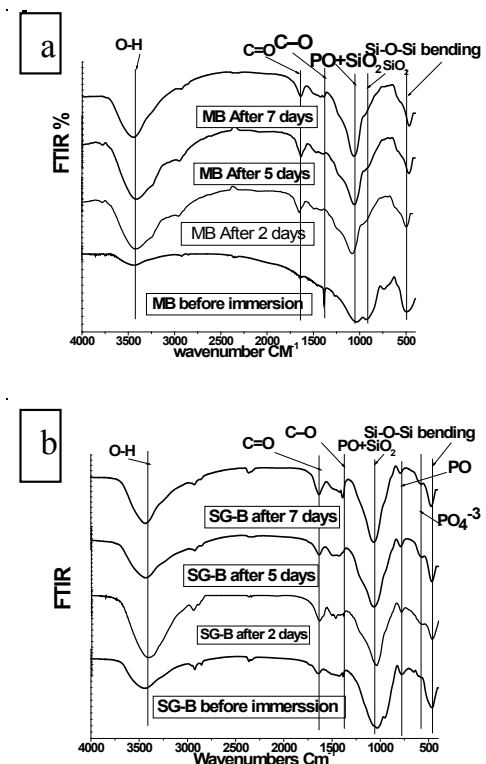

Figure 6: FTIR for samples a. MB and b. SG-B before and after immersion in SBF for 2, 5and 7 days. immersion in SBF at different periods. It is clearly evident almost the same spectra. However, after two days of immersion a band at 945 $\mathrm{cm}^{-1}$ of $\mathrm{SiO}_{2}$ for sample $\mathrm{MB}$ could be recognized, while, it is hardly observed for SG-B after the same period of immersion. After 7 days, the spectrum is quite similar to that of hydroxyapatite except two bands located at 1620 and $3423 \mathrm{~cm}^{-1}$. These absorptions bands are characteristic of the presence of water related to the hygroscopic feature of the formed apatite. The $\mathrm{OH}$ band at $3561 \mathrm{~cm}^{-1}$ is included in the $\mathrm{H}-\mathrm{O}-\mathrm{H}$ band at $3423 \mathrm{~cm}^{-1}$. The high water content is probably due to the presence of strong nucleophilic groups such as: $\mathrm{P}-\mathrm{OH}$ or $\mathrm{Ca}-\mathrm{OH}$, which favor the adsorption of the ambient humidity [7]. Also, it could be noticed that the intensity increase for bands at 600 and $740 \mathrm{~cm}^{-1}$ which is characteristic to $\mathrm{PO}_{4}^{3-}$ and $\mathrm{PO}$ assigned to crystalline calcium phosphate. However, for $\mathrm{MB}$ there are no notable changes for this band. This confirms the formation of HA layer on the surface of SG-B more faster than on $M B$ as proved by XRD results. Figure 7 shows the SEM micrographs for samples $\mathrm{MB}$ and SG-B before and after immersion in SBF at different time intervals. For both samples images $M B$ and SG-B before immersion a homogeneous amorphous bulk with almost uniform particles size has been observed. After immersion in SBF for two days there is no notable precipitation can be seen for MB but on the other hand for SG-B it could be noticed a layer of precipitated HA, which accumulate with the time to form a multi-layers of HA as it is evident after seven days. This is in agreement with the results of XRD and FTIR [1].

Cell viability was tested by MTT assays and is presented as histogram in Figure 8. The cells treated with different concentrations of the prepared samples showed relatively good cell viability compared to the control used as reference. The prepared bioactive glass by solgel method SG-B shows a higher tendency for cell growth at higher concentrations than those made by melting technique owing to their higher reactivity due to its smaller particle size and higher surface area resulted from shortened gelation time and thermal stability difference $[1,9,10,11]$.
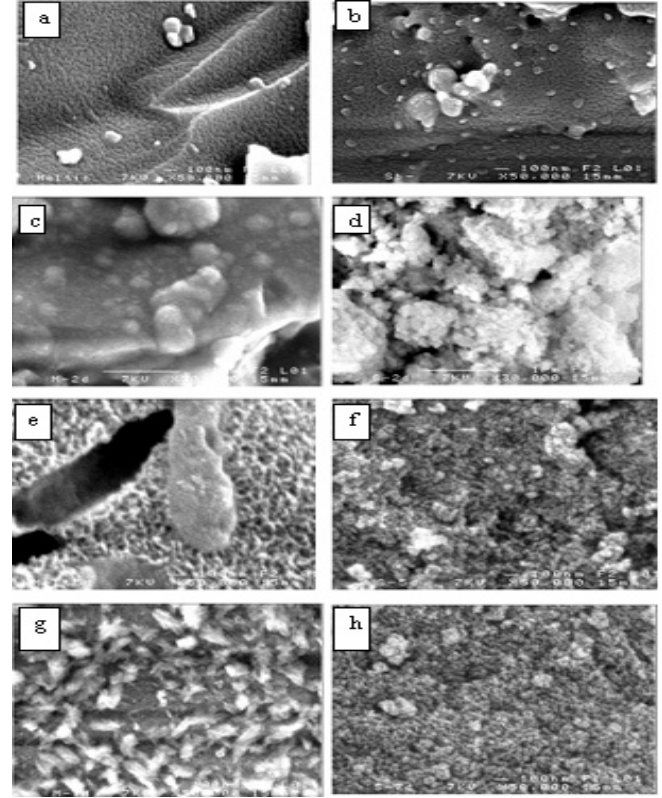

Figure 7: SEM micrographs; a, c, e and $\mathrm{g}$ for sample MB before and after immersion in SBF for 2,5, 7 days and $b, d$, $f$ and $h$ for sample SG-B before and after immersion in SBF for $2,5,7$ days, respectively. 
Citation: Mabrouk M, Mostafa AA, Oudadesse H, Wers E, Lucas-Girot A, et al. (2014) Comparative Study of Nanobioactive Glass Quaternary System 46S6. Bioceram Dev Appl 4: 072. doi: 10.4172/2090-5025.1000072

Page 4 of 4

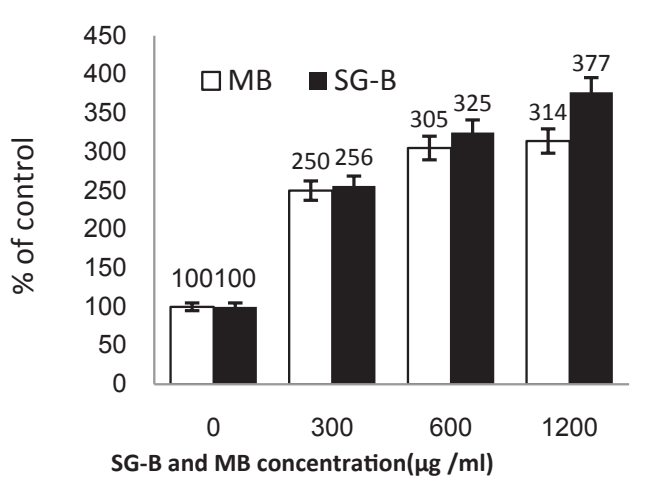

Figure 8: MTT assay of MB and SG-B after 48 hour of exposure.

\begin{tabular}{|c|c|c|c|c|}
\hline Sample Name & $\mathbf{S i O}_{2} \%$ & $\mathbf{C a O} \%$ & $\mathbf{N a}_{2} \mathbf{O} \%$ & $\mathbf{P}_{2} \mathbf{O}_{5} \%$ \\
\hline SG-B & 47.49 & 24.8 & 20.58 & 6.73 \\
\hline MB & 44.04 & 27.71 & 20.62 & 6.31 \\
\hline
\end{tabular}

Table 1: Chemical analysis of MB and SG-b by XRF.

\section{Conclusions}

Nanobioactive quaternary glass system $46 \mathrm{~S} 6$ has been prepared by modified sol-gel (acid-base reaction) method at $600^{\circ} \mathrm{C}$ with particle size ranging between $40-60 \mathrm{~nm}$ and a decrease in the gelation time. The formation of apatite layer over the sol-gel prepared glass was faster than in melting bioglass after immersion in simulated body fluid. Cell viability by MTT assay confirmed the effectiveness of the prepared bioactive glass nanopowder SG-B as a bone replacement material.

\section{Acknowledgment}

This work was financially supported by Campus France and Academy of Scientific Research and Technology (ASRT) of Egypt, Imhotep program.

\section{References}

1. Pereira MM, Clarck AE, Hench LL (1994) Journal of Materials, Synthesis and Processing 2: 189-195.

2. Sepulveda P, Jones JR, Hench LL (2001) Characterization of melt-derived $45 \mathrm{~S} 5$ and sol-gel-derived $58 \mathrm{~S}$ bioactive glasses. J Biomed Mater Res 58: 734-740.

3. Theodorou G, Goudouri OM, Kontonasaki E (2011) Comparative Bioactivity Study of $45 \mathrm{~S} 5$ and 58S Bioglasses in Organic and Inorganic Environment. Bioceramics Development and Applications 1:1-4.

4. Mezahi FZ, Lucas-Girot A, Oudadesse H, Harabi A (2013) Reactivity kinetics of $52 \mathrm{~S} 4$ glass in the quaternary system $\mathrm{SiO}_{2}-\mathrm{CaO}-\mathrm{Na}_{2} \mathrm{O}-\mathrm{P}_{2} \mathrm{O}_{5}$ : Influence of the synthesis process: Melting versus sol-gel. J Non-Cryst. Solids 361: 111-18.

5. Siqueira R.L, Peitl O, Zanotto ED (2011) Gel-derived $\mathrm{SiO}_{2}-\mathrm{CaOONa} \mathrm{O}_{2}-\mathrm{P}_{2} \mathrm{O}_{5}$ bioactive powders: synthesis and in vitro bioactivity. Mat. Sci. and Eng. $\mathrm{C}^{2}$ 31:983-991.

6. Radin S, Ducheyne P, Rothman B, Conti A (1997) The effect of in vitro modeling conditions on the surface reactions of bioactive glass. J Biomed Mater Res 37: 363-375.

7. Oudadesse H, Dietrich E, Gal YL, Pellen P, Bureau B, et al. (2011) Apatite forming ability and cytocompatibility of pure and $\mathrm{Zn}$-doped bioactive glasses. Biomed Mater 6: 035006.

8. Dietrich E, Oudadesse H, Lucas-Girot A, Mami M (2009) In vitro bioactivity of melt-derived glass $46 \mathrm{~S} 6$ doped with magnesium. J Biomed Mater Res A 88: 1087-1096.

9. Höland W, Vogel W, Naumann K, Gummel J (1985) Interface reactions between machinable bioactive glass-ceramics and bone. J Biomed Mater Res 19: 303-312.

10. Webster TJ, Ergun C, Doremus RH, Siegel RW, Bizios R (2001) Enhanced osteoclast-like cell functions on nanophase ceramics. Biomaterials 22: 1327-1333.

11. Brinker CJ, Scherer GW (1990) Sol-gel Science. Academic Press, Inc. 